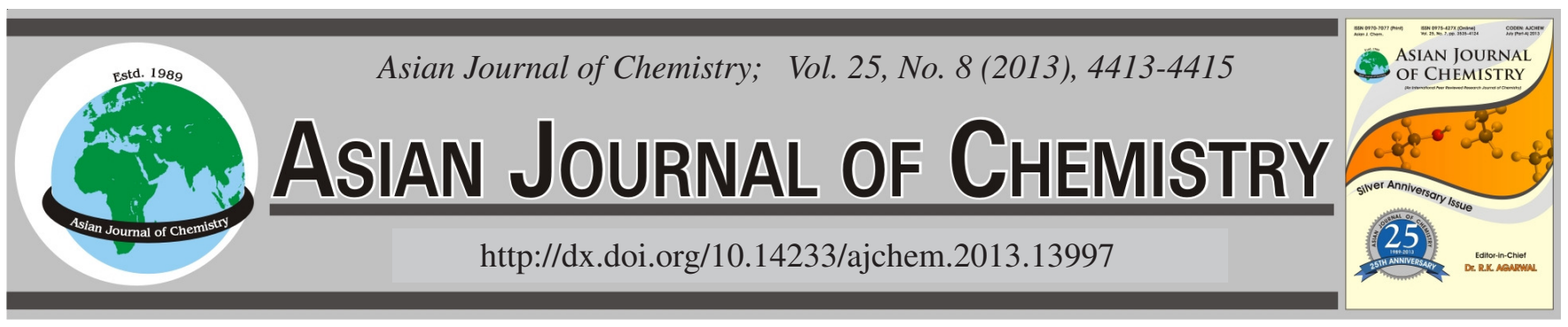

\title{
Improvement and Conditions Optimization of a Carbon Dioxide Successive Determining Test Method
}

\author{
DaO-Lin PAng, Chao Jin and FAng Li"
}

Center for Degradable and Flame-Retardant Polymeric Materials, National Engineering Laboratory for Eco-Friendly Polymeric Materials (Sichuan), College of Chemistry, Sichuan University, Chengdu 610064, P.R. China

*Corresponding author: E-mail: wblf92@scu.edu.cn

\section{INTRODUCTION}

The method, determination of ultimate aerobic biodegradability of plastic materials under controlled composing conditions, is an international standards method ${ }^{1}$ for determining the biodegradation rate of biodegradable polymers. The standard ISO14855 specifies a method for determining the biodegradation rate by gravimetric measurement of the amount of $\mathrm{CO}_{2}$. It was already applied widely in degradation ${ }^{2-4}$ of polymers in laboratories and offered an important property parameter for a new polymer. Zhang et $a l^{5}$, had used the measurement method of alkali absorption to replace the gravimetric way for improving the precision. Infrared absorption method and chromatographic techniques were also used in the determination ${ }^{6-8}$.

The determination of ultimate aerobic biodegradability of plastic materials is a long time process. The period is always more than 2 months. As far as authors knew, those determination methods mentioned above except for chromatographic method couldn't meet the requirement of successive measurement in so long time. And the carrier gas of chromatographic method is waste seriously. Those disadvantages restrict the determination method of polymers being applied in large scale. In this paper, we report the results of the improvement and conditions optimization of a carbon dioxide successive determining method for solving those disadvantages mentioned above.

\section{EXPERIMENTAL}

Method establishment: A measurement system for simulating real one of determination of ultimate aerobic biodegradability of plastic materials was established. The system is made up of 4 subsystems i.e., carrier gas supply and purge system, $\mathrm{CO}_{2}$ generator system, absorption system and exhaust gas treatment system. Total 8 air valves used to control the flow velocity in system and for safety. The original patterns of the system is shown in figure A.1 of ISO14855-22 ${ }^{1}$.

Carrier gas supply and purge system: Carrier gas was supplied by a mechanical gas pump. The output power is $35 \mathrm{~W}$ and gas supply rate is $40 \mathrm{~L} \mathrm{~min}^{-1}$ of the pump.

The gas supplied by pump was pumped through a gas purge system which had been made of 3 bottles with $2 \mathrm{~mol} \mathrm{~L}^{-1}$ $\mathrm{NaOH}$ and a bottle with saturated $\mathrm{Ca}(\mathrm{OH})_{2}$ solution for removing and determining the $\mathrm{CO}_{2}$ of air.

$\mathrm{CO}_{2}$ Generator system: $\mathrm{CO}_{2}$ generator system was used to generate $\mathrm{CO}_{2}$ quantitatively. Solid of $\mathrm{Na}_{2} \mathrm{CO}_{3}$ was dried in muffle furnace with $350{ }^{\circ} \mathrm{C}$ and $3.5 \mathrm{~h}$ and then was solved in deionized water quantitatively. The solution was dropped in excess $\mathrm{H}_{2} \mathrm{SO}_{4}$ of $0.5 \mathrm{~mol} \mathrm{~L}^{-1}$ with the rate 2 droplets per second. The chemical reaction was described as the reaction equation below:

$$
\mathrm{CaCO}_{3}+\mathrm{H}_{2} \mathrm{SO}_{4} \longrightarrow \mathrm{CaSO}_{4}+\mathrm{CO}_{2} \uparrow
$$

The $\mathrm{CO}_{2}$ generator system was positioned on a thermostatic magnetic stirrer for keeping the temperature of $\mathrm{CO}_{2}$ generated at $58^{\circ} \mathrm{C}$. 
The $\mathrm{CO}_{2}$ generated was accessed into absorption system by the carrier gas.

Absorption system: Absorption system was made of drier subsystem and absorption subsystem. The drier subsystem was made of a condensation bottle and 2-staged drier bottles. Four kinds of desiccant were chosen and measurement: $98 \% \mathrm{H}_{2} \mathrm{SO}_{4}$, silica gel, $\mathrm{CaCl}_{2}$ and $3 \mathrm{~A}$ molecular sieve.

The absorption subsystem was made of 4-staged absorption bottles. Three kinds of absorbent were chosen and measurement: soda lime granular, $2 \mathrm{~mol} \mathrm{~L}^{-1} \mathrm{NaOH}$ solution and $4 \mathrm{~A}$ molecular sieve.

Exhaust gas treatment system: Exhaust gas treatment system was made of a bottle of saturated $\mathrm{Ca}(\mathrm{OH})_{2}$ for determining the $\mathrm{CO}_{2}$ absorption degree of absorption system and a foam flow meter for measuring the real gas flow velocity of whole system.

Operation of system: The system was run a definable period of time in each experiment. The gross weights of absorption subsystem were weighed at the beginning and the end of each experiment. The value of theoretical yield of $\mathrm{CO}_{2}$ was via dripping the volume amount of $\mathrm{Na}_{2} \mathrm{CO}_{3}$. Deionized water was dripped into system for letting the gross liquid addition amount be up to $70 \mathrm{~mL}$ each experiment.

\section{Conditions optimization experiment}

Desiccant: The 4 kinds of desiccant were filled in the bottles of drier subsystem and then ran the system 3 times for $10 \mathrm{~h}$ each time in turn. $70 \mathrm{~mL}$ deionized water was dripped into system every time and the soda lime granular was used to be the absorbent. Flow velocity region was controlled in $10-13 \mathrm{~mL} / \mathrm{min}$

Average weight increment $\Delta \overline{\mathrm{m}}$ was used to be the assessment index of effect quality of desiccant. The less the value of $\Delta \overline{\mathrm{m}}$ is relatively, the better the drying performance of desiccant.

Responsibility and absorption volume of absorbent: Three kinds of absorbent were filled in the bottles of absorption subsystem respectively and then ran the system 3 times for $3 \mathrm{~h}$ each time in turn. A series of different weights of $\mathrm{CO}_{2}$ were generated for per series of testing of using one same absorbent and $\mathrm{CaCl}_{2}$ was used to be the desiccant. Flow velocity region was controlled in $10-13 \mathrm{~mL} / \mathrm{min}$.

Responsibility was defined as the real weight increment corresponding to theoretical value. Theoretical value region was $0.0934-0.934 \mathrm{~g}$.

Absorption volume was defined as the real weight increment corresponding to big theoretical value. Theoretical values were set as $0.25,0.5,1,2,3$ times as the $\mathrm{CO}_{2}$ yield of $10 \mathrm{~g}$ microcrystalline cellulose been degraded completely.

Flow velocity region: Real weight increments of different theoretical yields of $\mathrm{CO}_{2}$ were measured in different flow velocity regions for $3 \mathrm{~h}$ each time. The soda lime granular was used to be the absorbent and $\mathrm{CaCl}_{2}$ was used to be the desiccant.

\section{RESULTS AND DISCUSSION}

Desiccant: Although result of using 3A molecular sieve had the minimum value (Table-1), it is a broad-spectrum gas,
TABLE-1

RESULTS OF $\Delta \overline{\mathrm{m}}$ WITH DIFFERENT DESICCANTS

\begin{tabular}{lccccc}
\multicolumn{1}{c}{ Desiccent } & $\begin{array}{c}\text { Amount } \\
(\times 2)\end{array}$ & $\begin{array}{c}\Delta \overline{\mathrm{m}} \\
(\mathrm{g})\end{array}$ & Desiccent & $\begin{array}{c}\text { Amount } \\
(\times 2)\end{array}$ & $\begin{array}{c}\Delta \overline{\mathrm{m}} \\
(\mathrm{g})\end{array}$ \\
\hline $98 \% \mathrm{H}_{2} \mathrm{SO}_{4}$ & $500 \mathrm{~mL}$ & 0.17 & $\mathrm{CaCl}_{2}$ & $500 \mathrm{~g}$ & 0.04 \\
Silica gel & $500 \mathrm{~g}$ & 0.24 & Molecular sieve & $500 \mathrm{~g}$ & 0.02 \\
\hline
\end{tabular}

including $\mathrm{CO}_{2}$, descant and may absorb the measured gas. $\mathrm{CaCl}_{2}$ is the best choice of the 4 desiccants.

Absorbent: The responsibility curve of soda lime granular has the best liner correlation (highest value of related coefficient) and the volume curve of soda lime granular has the minimum MSE. Soda lime granular is the best choice of the 3 absorbents (Fig. 1, Table-2).

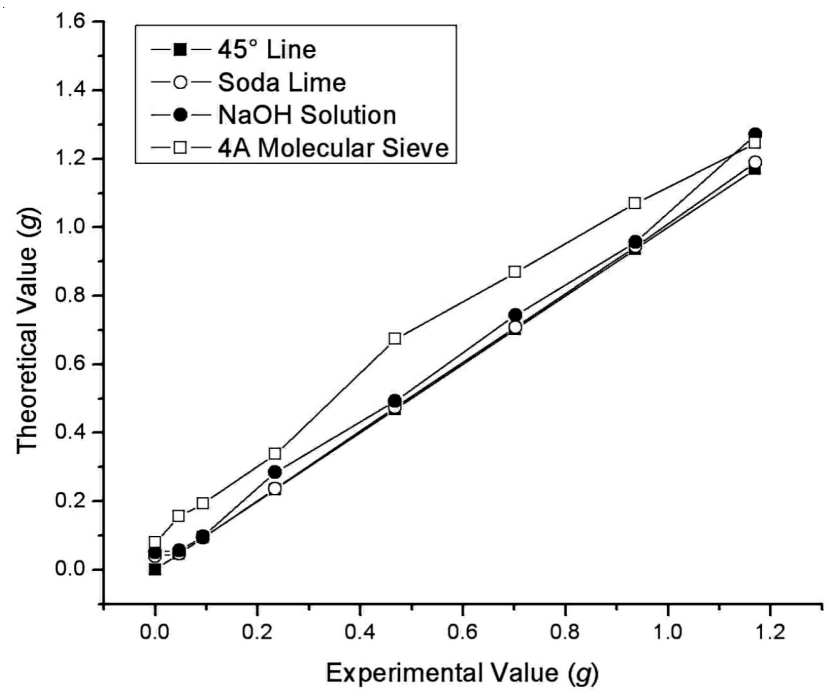

(A)

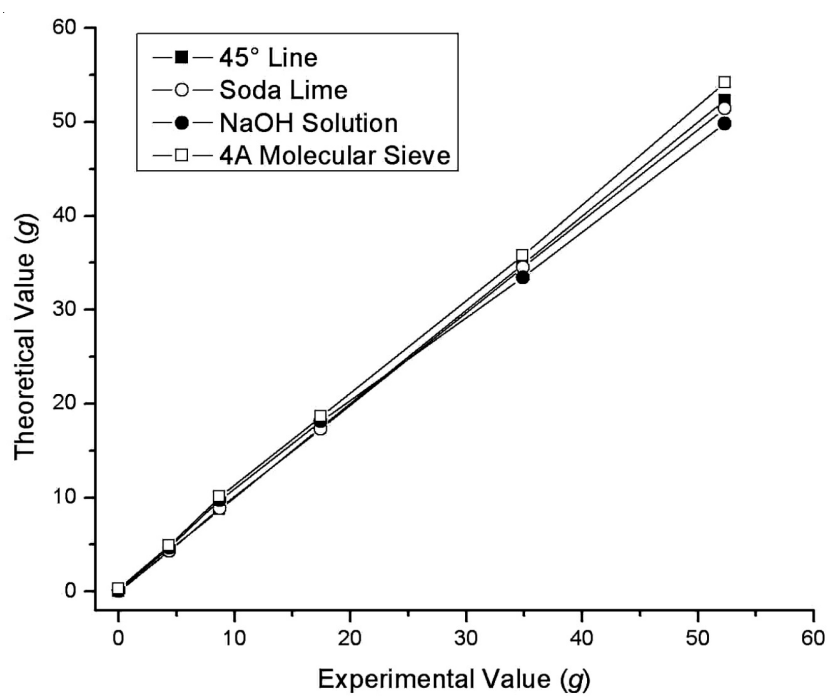

(B)

Fig. 1. Plot-plot images of theoretical and experimental values of absorption (A) and volume (B)

Flow velocity region: There is a mutation between the results and MSE of flow velocity 22.1-30.5 $\mathrm{mL} \mathrm{min}^{-1}$ observed from Fig. 2 and Table-3, respectively. These experimental evidences can support the conclusion that the best flow velocity for the method operation should be in the range of 5.2-22.1 $\mathrm{mL} \min ^{-1}$. 


\begin{tabular}{lccc}
\hline \multicolumn{4}{c}{ TABLE-2 } \\
MEAN STATISTICAL INDICATORS OF \\
\multicolumn{4}{c}{ RESPONSIBILITY AND VOLUME EXPERIMENTS } \\
\hline \multirow{2}{*}{ Absorbent } & Amount & Responsibility & Volume \\
& $(\times 4)$ & related coefficient & MSE \\
\hline Soda lime granular & $117-132 \mathrm{~g}$ & 0.9991 & 0.1661 \\
NaOH solution & $150 \mathrm{~mL}$ & 0.9968 & 1.1937 \\
4A molecular sieve & $140-152 \mathrm{~g}$ & 0.9901 & 0.2148 \\
\hline
\end{tabular}

\begin{tabular}{cccc}
\multicolumn{4}{c}{ TABLE-3 } \\
\multicolumn{4}{c}{ MEAN MSE OF FLOW VELOCITY EXPERIMENT } \\
\hline $\begin{array}{c}\text { Flow velocity } \\
\left(\mathrm{mL} \mathrm{min}^{-1}\right)\end{array}$ & MSE $\left(10^{-6}\right)$ & $\begin{array}{c}\text { Flow velocity } \\
\left(\mathrm{mL} \mathrm{min}^{-1}\right)\end{array}$ & MSE $\left(10^{-6}\right)$ \\
\hline $5.2-6.7$ & 8.9536 & $21.1-22.1$ & 28.8 \\
$9.8-11.1$ & 10.1 & $29.5-31.2$ & 921 \\
$15.3-17.1$ & 60.2 & $41.0-44.3$ & 1321 \\
\hline
\end{tabular}

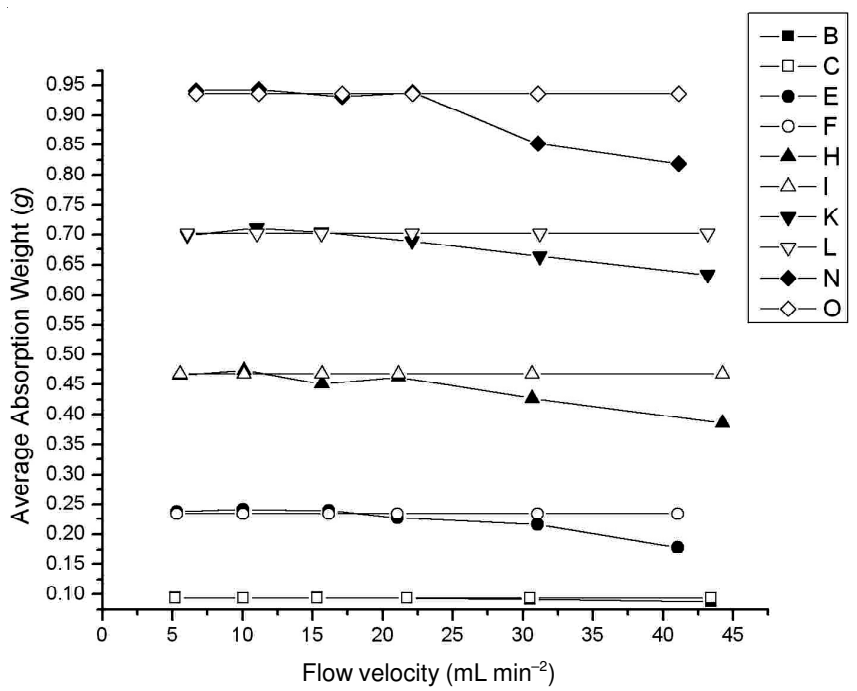

Fig. 2. Plot-plot images of theoretical and experimental values of flow velocity

\section{Conclusion}

The results obtained in these works that the improvement and conditions optimization show that it is possible to perform the successive determining of $\mathrm{CO}_{2}$ for the determination of ultimate aerobic biodegradability of plastic materials under controlled composing conditions. And the cost of agents and labor is lower than other methods known significantly. Therefore, the system could be applied in large scale. The kind of desiccant, $\mathrm{CaCO}_{3}$, is neutral and can be used very widely to dry gas except for the substance with activate hydroxyl groups. Its gas resistance is low and water absorption efficiency is enough for common industrial use. The system can be not only used in the degradation but also other conditions which need gas successive determination in long period via changing the absorbent. Those results can be a basement of automating the $\mathrm{CO}_{2}$ and other gas production measurements.

\section{REFERENCES}

1. ISO 14855-2 Determination of the Ultimate Aerobic Biodegradability of Plastic Materials Under Controlled Composting Conditions-Method by Analysis of Evolved Carbon Dioxide-Part 2: Gravimetric Measurement of Carbon Dioxide Evolved in a Laboratory-Scale Test [S].

2. S. Grima, V. Bellon-Maurel, F. Silvestre and P. Feuilloley, J. Polym. Environ., 9, 39 (2001).

3. L.H. Zhang, P.D. Lin, L. Chengyue, L. Fang, W. Xiuli and W. Yuzhong, Acta Polym. Sin., 6, 633 (2011)

4. C. Telemachus, M.D. Koliopoulos and G. Koliopoulou, Asian J. Chem., 20, 1153 (2008).

5. T.P. Huang, J. Chen, Q.Y. Yang, Y.K. Zhang and R.F. Ding, Asian J. Chem., 24, 2717 (2012).

6. G.J. Zhang, Y.P. Li and Q.B. Li, Opt. Las. Eng., 48, 1206 (2010).

7. M. Emran, M. Gispert and Giovanni Pardini, Geoderma, 170, 176 (2012).

8. L. Pilon, H. Berberoglu and R. Kandilian, J. Quant. Spectr. Radiat. Trans., 112, 2639 (2011). 